\title{
Embebição e Germinação de Sementes de Picão-Preto (Bidens pilosa) ${ }^{1}$
}

\author{
Imbibition and Germination of Hairy Beggartick Seeds (Bidens pilosa)
}

ADEGAS, F.S. ${ }^{2}$, VOLL, E. ${ }^{3}$ e PRETE, C.E.C. ${ }^{4}$

\begin{abstract}
RESUMO - Um experimento foi conduzido no laboratório da Embrapa Soja, Londrina-PR, com o objetivo de avaliar as correlações entre períodos de embebição, níveis de absorção de água e germinação das sementes da planta daninha Bidens pilosa (picão-preto). As sementes de picão-preto, colhidas em março de 1997, foram colocadas para embeber em água por períodos de $6,12,18,24$ e 48 horas. Em seguida, foi determinado o teor de água nas sementes e a condutividade elétrica dos seus exsudatos. A germinação foi avaliada em germinador com ciclo de 14/10 horas de luz fluorescente difusa e escura, respectivamente, com temperaturas respectivas de $30^{\circ} / 20^{\circ} \mathrm{C}$ e umidade relativa constante de $90 \pm 5 \%$. Foi usado o delineamento inteiramente casualizado, com quatro repetições, de 100 sementes. A porcentagem de germinação média foi de $87,5 \%$. A absorção de água teve aumento significativo com maiores períodos de embebição. Não houve correlação entre a germinação, os períodos de embebição de água e a condutividade elétrica. A capacidade de absorção de água e a condutividade elétrica apresentaram médio grau de correlação entre si. A germinação iniciou-se no terceiro dia, após início da embebição, e o pico foi alcançado no quinto dia. Os maiores índices de velocidade de germinação foram obtidos pelos maiores períodos de embebição das sementes.
\end{abstract}

Palavras-chave: condutividade elétrica, absorção de água, planta daninha.

ABSTRACT - An experiment was carried out at Embrapa Soja, in Londrina-PR, Brazil to determine the relationships between imbibition periods, water absorption levels and seed germination of the weed hairy beggartick (Bidens pilosa). Seeds were harvested from field plants in March 1997, and were set to imbibe for periods of 06,12,18, 24 and 48 hours. The water content of the seeds and the electric conductivity of their exudates were determined. Germination was also determined using a germinator set for cycles of 14/10 hours of diffuse fluorescent light and dark, respectively, at $30^{\circ} / 20{ }^{\circ} \mathrm{C}$ respective temperatures, and $90 \pm 5 \%$ constant relative humididty $(\mathrm{RH})$. A completely randomized design experiment, with four replications of 100 seeds each, was used. Average seed germination percentage was $87.5 \%$. Water absorption had a significant increase with longer imbibition periods. No correlation was observed among germination, water imbibition periods and electric conductivity. Water absorption capacity and electric conductivity presented a medium degree of correlation. Germination started on the third day and the peak was reached on the fifth day. The highest germination velocity index was obtained with the highest periods of seed imbibition.

Key words: electric conductivity, water absorption and weed.

\section{INTRODUÇÃO}

Bidens pilosa, vulgarmente conhecida como picão-preto, é uma planta originária da América tropical, largamente dispersa em várias regiões do mundo, ocorrendo em maior quantidade na América do Sul. No Brasil, é encontrada em praticamente todo o território, com maior concentração nas áreas agrícolas da Região Centro-Sul, onde se constitui numa

1 Recebido para publicação em 23.11.2001e na forma revisada em 2.4.2003.

2 Eng.-Agr., M.S., Área de Plantas Daninhas da EMATER-Paraná, Caixa Postal 231, 86001-970 Londrina-PR; ${ }^{3}$ Eng.-Agr., Ph.D., Pesquisador de Plantas Daninhas da Embrapa Soja. ${ }^{4}$ Eng.-Agr., Dr., Professor do Departamento de Fitotecnia da UEL, Caixa Postal 6001, 86051-990 Londrina-PR. 
das mais importantes plantas infestantes, tanto de culturas anuais como de perenes (Kissmann \& Groth, 1992).

Lorenzi (2000) descreve picão-preto como uma espécie de ciclo anual, herbácea, ereta, com altura entre 40 e $120 \mathrm{~cm}$, propagada via sementes, muito prolífera, de ciclo curto e com capacidade de produzir até três gerações por ano. As folhas são glabras, inteiras ou lobadas, sendo as superiores eventualmente internas, de 5 a $10 \mathrm{~cm}$ de comprimento. O fruto é um aquênio linear-tetragonal, de 5 a $9 \mathrm{~mm}$ de comprimento, coloração marrom-escura e com extremidade superior provida de 2-3 aristas.

A formação de sementes é intensa, podendo chegar a 3.000 por planta, e, após a maturação, poucas sementes têm germinação imediata (Kissmann, 1997). Essa latência das sementes de Bidens pilosa ocorre devido ao fenômeno da dormência, o que proporciona a sobrevivência e a viabilidade do banco sementes em condições externas adversas (Voll et al., 1997).

Chivinge (1996) observou que $20^{\circ}$ a $35^{\circ} \mathrm{C}$ é o melhor intervalo de temperatura para germinação de sementes de picão-preto, com o máximo (70\%) ocorrendo a $25^{\circ} \mathrm{C}$, o que foi comprovado também por Rios et al. (1989).

A germinação de sementes de picão-preto pode ocorrer na ausência de luz (Klein \& Fellipe, 1991). Amaral \& Takaki (1998), estudando a estrutura dos aquênios dessa espécie, verificaram que os aquênios com tegumento verrugoso mostraram dormência e sensibilidade à luz, ao passo que os aquênios sem ornamento no tegumento não apresentaram dormência nem sensibilidade à luz, durante o processo de germinação.

As sementes de picão-preto germinam facilmente até $1 \mathrm{~cm}$ de profundidade; quando em profundidades maiores que $10 \mathrm{~cm}$, podem permanecer dormentes por vários anos (Lorenzi, 2000). Sahoo \& Jha (1998) obtiveram redução de $66 \%$ na germinação da espécie quando as sementes foram semeadas a apenas $2 \mathrm{~cm}$ de profundidade.

A água é essencial para a germinação das sementes de plantas daninhas, pois o processo só se inicia com a embebição da semente. Segundo Popinigis (1985), a taxa de germinação das sementes está intimamente relacionada com a tensão de água no solo e com o período de absorção de água, entre outros fatores. Voll et al. (1997) observaram que as sementes de Brachiaria plantaginea apresentaram aumento linear de absorção de água até 48 horas de embebição. Mikusinski (1987) constatou que sementes de Ipomoea aristolochiaefolia só germinavam quando atingiam $72 \%$ de absorção de água, porém $60 \%$ delas eram duras. No que se refere ao picão-preto, há pouca informação sobre o assunto. Reddy \& Singh (1992) verificaram que, com o aumento do período de embebição, a germinação dessas sementes diminuía, até cessar, aos 28 dias. Todavia, Chivinge (1996) constatou que, apesar de as sementes de picão-preto já terem iniciado o processo de germinação em menos de 24 horas de embebição, a maior porcentagem de germinação (59\%) ocorreu apenas com cinco dias de embebição.

O objetivo deste trabalho foi verificar a correlação entre períodos de embebição, níveis de absorção de água, condutividade elétrica e germinação de sementes de picão-preto.

\section{MATERIAL E MÉTODOS}

O experimento foi conduzido no laboratório da Embrapa Soja, em Londrina-PR, em abril de 1997. Foi utilizada uma amostra de 1.000 sementes de picão-preto colhido durante o mês de março do mesmo ano.

Foi usado o delineamento experimental inteiramente casualizado, com quatro repetições, cada uma composta de uma subamostra de 100 sementes, retiradas da amostra inicial. A determinação da umidade foi realizada acondicionando essas subamostras de sementes em ampolas metálicas, previamente pesadas, e levadas à estufa com circulação de ar forçada, regulada a $105 \pm 3{ }^{\circ} \mathrm{C}$ por 24 horas, sendo novamente pesadas (Brasil, 1992).

Na seqüência, essas subamostras foram distribuídas em um condutivímetro modelo ASA-610, sendo depositadas cinco sementes por célula do equipamento, ficando imersas em água destilada e deionizada, mantidas em temperatura ambiente de $20^{\circ} \mathrm{C}$ por períodos de embebição de $6,12,18,24$ e 48 horas. Após cada período de embebição, com as mesmas subamostras, foram determinadas 
primeiramente a condutividade elétrica, depois a taxa de absorção de água e, por último, a porcentagem de germinação das sementes.

Seguindo a metodologia de Krzyzanowski et al. (1991), a condutividade elétrica (CE) das sementes foi determinada com a leitura do condutivímetro a 4 volts, após cada período de embebição, na própria solução onde as sementes permaneceram embebidas.

A taxa de absorção de água foi calculada pela relação entre o peso inicial das sementes e o peso das sementes obtido após a embebição em água.

A germinação das sementes foi conduzida em caixas tipo gerbox. Cada subamostra de 100 sementes foi distribuída de modo uniforme sobre quatro folhas de papel-filtro, umedecidas com $12 \mathrm{ml}$ de água. As caixas tipo gerbox foram colocadas em germinador, sob ciclos de 14/ 10 horas de luz fluorescente difusa e escura, a $30 / 20{ }^{\circ} \mathrm{C}$, com umidade relativa de $90 \pm 5 \%$. Foram feitas contagens diárias da germinação das sementes durante sete dias. As sementes foram consideradas germinadas quando a protrusão da radícula através do tegumento se tornou visível. A velocidade de germinação diária foi calculada pela razão entre a germinação ocorrida no dia e o total de sementes germinadas no período total, multiplicado por 100 .

A determinação do índice de velocidade de germinação das sementes foi feita conforme Maguire (1962), por meio de contagens diárias do número de sementes germinadas.

Os dados obtidos foram submetidos à análise de variância e ao teste $\mathrm{F}$ de significância, a $5 \%$ de probabilidade. Também foram feitos ajustes das equações de regressão, com análise de significância.

\section{RESULTADOS E DISCUSSÃO}

Antes da realização dos testes, as sementes estavam com $12,3 \%$ de umidade e peso de $2,665 \mathrm{~g} / 1.000$ sementes.

Houve efeitos significativos de períodos de embebição de sementes de picão-preto na taxa de absorção de água. Todavia, não foram observados efeitos significativos de períodos de embebição na condutividade elétrica dos exsudatos e na sua porcentagem de germinação de sementes, como mostra a Tabela 1 .

A correlação entre a quantidade de água absorvida e a germinação de sementes, em função do período de embebição, está apresentada na Figura 1. O teor de água absorvido pelas sementes aumentou significativamente com o período de embebição, que pôde ser representado por uma equação de regressão linear, com alto ajuste aos dados. O teor de água, que após seis horas de embebição era de 65,3, atingiu o máximo de $105,3 \%$ com 48 horas.

Tabela 1 - Absorção de água, condutividade elétrica e germinação das sementes de picão-preto em função do período de embebição

\begin{tabular}{|c|c|c|c|}
\hline $\begin{array}{c}\text { Embebição } \\
\text { (horas) }\end{array}$ & $\begin{array}{c}\text { Absorção de } \\
\text { água (\%) }\end{array}$ & $\begin{array}{c}\text { Condutividade } \\
\text { elétrica }(\mu \mathrm{A})\end{array}$ & $\begin{array}{c}\text { Germinação } \\
(\%)\end{array}$ \\
\hline 6 & $65,3 \mathrm{~d}$ & 96,5 & 88,5 \\
12 & $77,4 \mathrm{c}$ & 101,6 & 91,5 \\
18 & $88,4 \mathrm{~b}$ & 99,4 & 84,5 \\
24 & $91,7 \mathrm{~b}$ & 101,1 & 87,5 \\
48 & $105,3 \mathrm{a}$ & 104,0 & 85,8 \\
\hline F (.05) & $51,65^{*}$ & 0,66 & 0,95 \\
$\mathrm{CV}(\%)$ & 4,91 & 6,82 & 6,32 \\
\hline
\end{tabular}

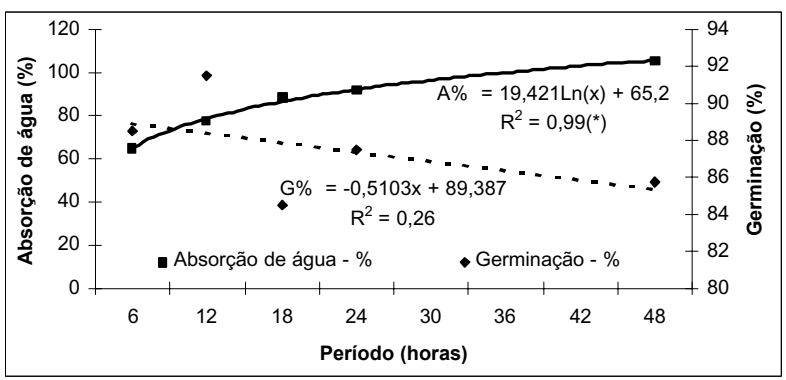

Figura 1 - Efeito de diferentes períodos de embebição na absorção de água e germinação de sementes de picão-preto.

Não houve efeito significativo para a germinação de sementes de picão-preto, que foi representada por uma equação linear, de tendência negativa, com baixo coeficiente de ajuste $\left(r^{2}=0,26\right)$. A germinação máxima, de $91,5 \%$, correspondeu ao período de embebição de 12 horas, e a germinação média foi alta, de $87,5 \%$, concordando com os resultados obtidos por Holm et al. (1977). Reddy \& Singh (1992) 
observaram que sementes de Bidens pilosa tinham a taxa de germinação reduzida com aumentos de períodos de embebição, obtendo $56 \%$ de germinação para embebição momentânea, 25\% para um dia de embebição, 16\% para três dias de embebição, até chegar aos 28 dias de embebição, em que não ocorreu mais a germinação das sementes. Isso, em parte, pode explicar a baixa incidência de picão-preto em áreas de solos propensas a períodos de inundação.

Segundo alguns autores, como AOSA (1983) e Marcos Filho et al. (1987), as determinações de condutividade elétrica são afetadas por diversos fatores da planta, do meio ambiente e da metodologia utilizada, sendo o período de embebição um deles. Não foi observada diferença estatística na condutividade elétrica. A Figura 2 mostra os níveis de lixiviação eletrolítica das sementes de picão-preto, que se iniciou com $96,5 \mu \mathrm{A}$ para 6 horas e atingiu o máximo de 104,0 $\mu \mathrm{A}$ com 48 horas de embebição das sementes. A condutividade elétrica, observada após o período-padrão de embebição de 24 horas, foi de $101,6 \mu \mathrm{A}$, usando cinco sementes por célula, ou $20,32 \mu \mathrm{A}$ por semente.

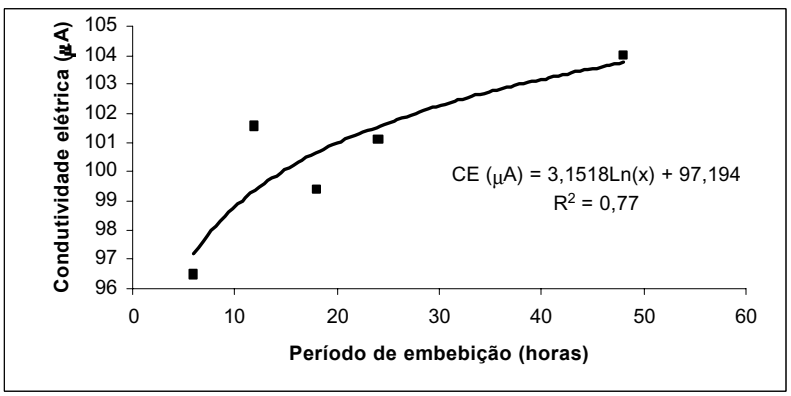

Figura 2 - Condutividade elétrica de sementes de picão-preto submetidas a diferentes períodos de embebição.

Na Figura 3 são apresentadas as relações entre a condutividade elétrica e a absorção de água e também entre a condutividade elétrica e a germinação das sementes de picão-preto. O aumento da absorção de água resultou em aumento linear e significativo da condutividade elétrica, indicando que a lixiviação de íons do interior das sementes estaria associada à quantidade de água absorvida durante o processo de germinação. No entanto, o aumento da condutividade elétrica não mostrou correlação alguma com a taxa de germinação $\left(R^{2}=0,007\right)$, o que pode ser explicado por danos causados nas membranas, decorrentes da rápida embebição das sementes, resultando nessa redução na germinação.

As curvas de germinação diária de diferentes períodos de embebição das sementes estão apresentadas na Figura 4. Para todos os períodos de embebição a germinação foi iniciada no terceiro dia e encerrada no sétimo dia, sendo o maior índice verificado no quinto dia. Quanto maior o período de embebição, maior a taxa inicial de germinação. Todavia, a partir do quinto dia a situação foi invertida, pois os menores períodos de embebição proporcionaram as maiores taxas de germinação, com a embebição de apenas seis horas, resultando na maior taxa de germinação de todo o período, que foi de $14,1 \%$.
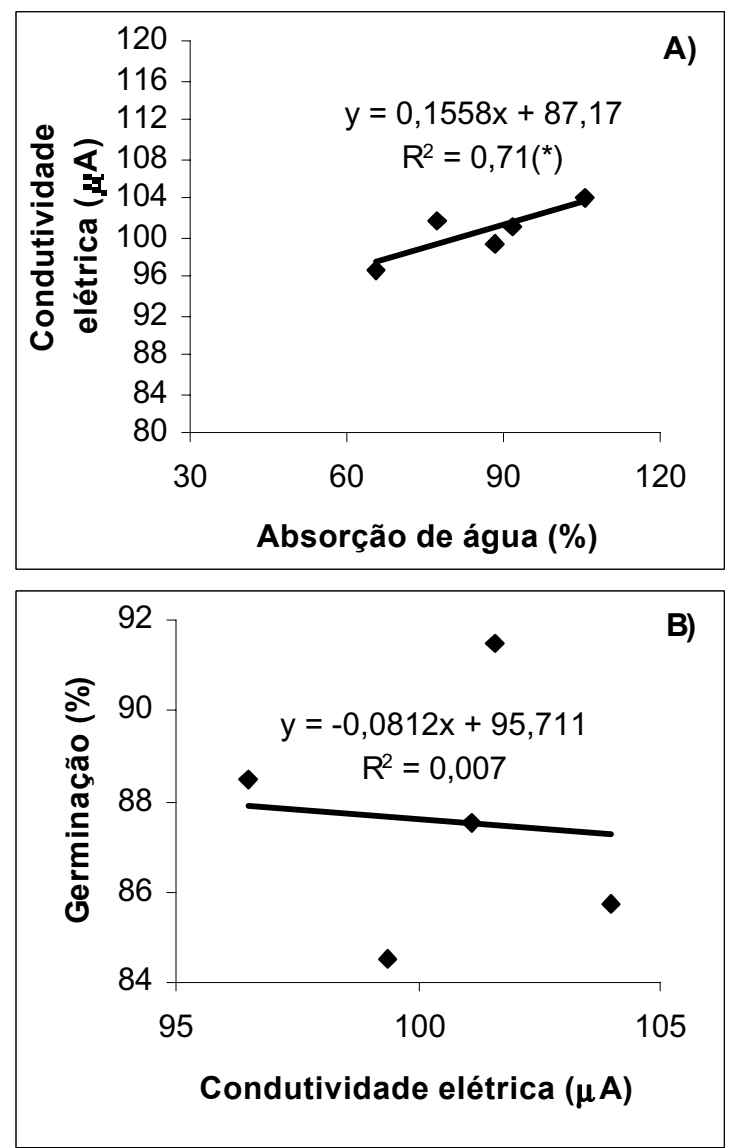

Figura 3 - Relação entre teor de água absorvida e condutividade elétrica dos exsudatos (A) e entre a condutividade elétrica dos exsudatos e a germinação (B) durante a embebição de sementes de picão-preto por 48 horas. 


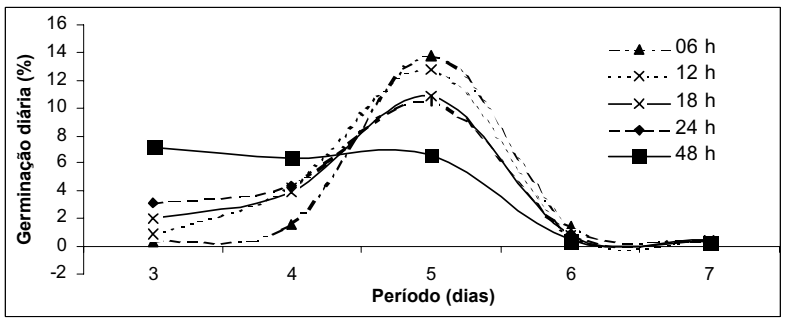

Figura 4 - Velocidade de germinação diária de sementes de picão-preto, para diferentes períodos de embebição em água.

Em razão de o comportamento da maior germinação inicial de picão-preto ocorrer com o maior período de embebição das sementes, a germinação cumulativa, expressa na Figura 5 pelo índice de velocidade de germinação (IVG), mostra que, quanto maior o período de embebição, maiores os IVGs obtidos.

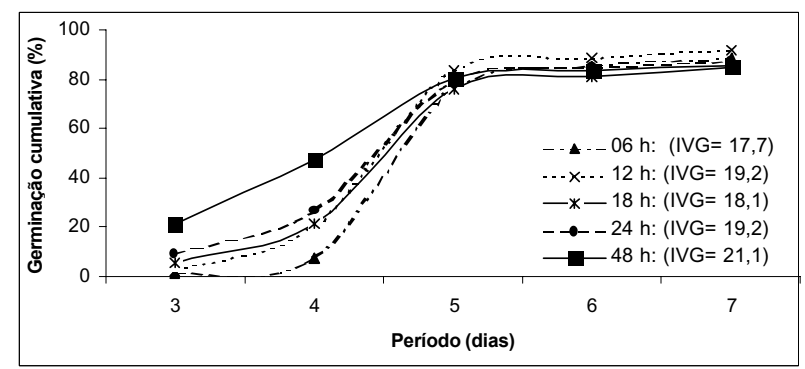

Figura 5 - Germinação diária cumulativa de sementes de picãopreto, para diferentes períodos de embebição em água.

\section{LITERATURA CITADA}

AMARAL, A.; TAKAKI, M. Achene dimorphism in Bidens pilosa $\mathrm{L}$. as determined by germination test. Braz. Arch. Biol. Technol., v. 41, n. 1, p. 11-16, 1998.

BRASIL. Ministério da Agricultura e Reforma Agrária. Regras para análise de sementes. Brasília-DF: SNDA/ DNDV/CLAV, 1992. 365 p.

CHIVINGE, O. A. Studies on the germination and seedling emergence of Bidens piloa and its response to fertilizer application. Trans. Zimb. Scient. Assoc., v. 70, p. 1-5, 1996.
HOLM, L. G. et al. The World's Worst Weeds.

Distribution and biology. Honolulu. University Press of Hawaii, 609 p. 1977.

KISSMANN, C. G.; GROTH, D. Plantas infestantes e nocivas. São Paulo: BASF Brasileira. 1992. 798 p. t. II

KISSMANN, C. G. Bidens pilosa L. e Bidens subalternans DC. São Paulo: BASF Brasileira. 1997. 6 p. (mimeografado).

KLEIN, A.; FELLIPE, G. M. Efeitos da luz na germinação de sementes de ervas invasoras. Pesq. Agrop. Bras., v. 26, n. 7, p. 955-966, 1991.

KRZYZANOWSKI, F. C.; FRANÇA NETO, J. B.;

HENNING, A. A. Relato dos testes de vigor disponíveis para as grandes culturas. Inform. ABRATES, v. 1, n. 2, p. 15-50, 1991.

LORENZI, H. Plantas daninhas do Brasil: terrestres, aquáticas, parasitas, tóxicas e medicinais. 3.ed. Nova Odessa: Instituto Plantarum, 2000. 608 p.

MAGUIRE, J. D. Speed of germination-aid in selection and evaluation for seedling emergence and vigor. Crop Sci., v. 2, n. 1, p. 176-177, 1962.

MIKUSINSKI, O. M. Teste de embebição e germinação em sementes de Ipomoea aristolochiaefolia (HBH). R. Bras. Sem., v. 9, n. 3, p. 103-108, 1987.

POPINIGIS, F. Fisiologia da semente. Brasília: AGIPLAN, 1985. 289 p.

REDDY, K. N.; SINGH, M. Germination and emergence of hairy beggarticks (Bidens pilosa). Weed Sci., v. 40, n. 2, p. 195-199, 1992.

RIOS, A.; MANTOVANI, E.; SEDIYAMA, C. Efeito da temperatura na germinação de frutos polimórficos de Bidens pilosa L. Malezas, v. 17, n. 2, p. 20-26, 1989.

SAHOO, U.K.; JHA, L.K. Effect of depth and duration of burial on seed viability and dormancy of Bidens pilosa L. and Richardsonia pilosa H. B. K. Seed Res., v. 25, n. 1, p. 5-10, 1998.

VOLL, E. et al. Embebição e germinação de sementes de capim-marmelada. R. Bras. Sem., v. 19, n. 1, p. 58-61, 1997. 